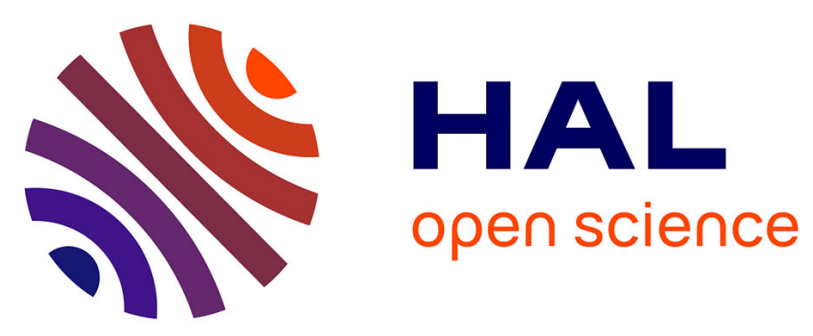

\title{
Honeycomb Organization of Chitin Nanocrystals (ChNCs) in Nanocomposite Films of UV-Cured Waterborne Acrylated Epoxidized Soybean Oil Emulsified with ChNCs
}

Fatma Ben Cheikh, Ayman Ben Mabrouk, Albert Magnin, Christine

Lancelon-Pin, Jean-Luc Putaux, Sami Boufi

\section{To cite this version:}

Fatma Ben Cheikh, Ayman Ben Mabrouk, Albert Magnin, Christine Lancelon-Pin, Jean-Luc Putaux, et al.. Honeycomb Organization of Chitin Nanocrystals (ChNCs) in Nanocomposite Films of UVCured Waterborne Acrylated Epoxidized Soybean Oil Emulsified with ChNCs. Biomacromolecules, 2021, 22 (9), pp.3780 - 3790. 10.1021/acs.biomac.1c00612 . hal-03344141

HAL Id: hal-03344141

https://cnrs.hal.science/hal-03344141

Submitted on 14 Sep 2021

HAL is a multi-disciplinary open access archive for the deposit and dissemination of scientific research documents, whether they are published or not. The documents may come from teaching and research institutions in France or abroad, or from public or private research centers.
L'archive ouverte pluridisciplinaire HAL, est destinée au dépôt et à la diffusion de documents scientifiques de niveau recherche, publiés ou non, émanant des établissements d'enseignement et de recherche français ou étrangers, des laboratoires publics ou privés. 


\section{Honeycomb organization of chitin nanocrystals (ChNCs) in nanocomposite films of $\mathrm{UV}$-cured waterborne acrylated epoxidized soybean oil emulsified with $\mathrm{ChNCs}$}

Fatma Ben Cheikh ${ }^{\mathrm{a}}$, Ayman Ben Mabrouk ${ }^{\mathrm{a}}$, Albert Magnin ${ }^{\mathrm{b}}$, Christine Lancelon-Pin ${ }^{\mathrm{c}}$, Jean-Luc Putaux ${ }^{\mathrm{c}}$, Sami Boufi ${ }^{\mathrm{a},}$

${ }^{a}$ University of Sfax, LMSE, Faculty of Science, BP 802, 3018 Sfax, Tunisia

${ }^{b}$ Univ. Grenoble Alpes, CNRS, Grenoble INP, LRP, F-38000 Grenoble, France

${ }^{c}$ Univ. Grenoble Alpes, CNRS, CERMAV, F-38000 Grenoble, France

* Corresponding author: sami.boufi@fss.rnu.tn

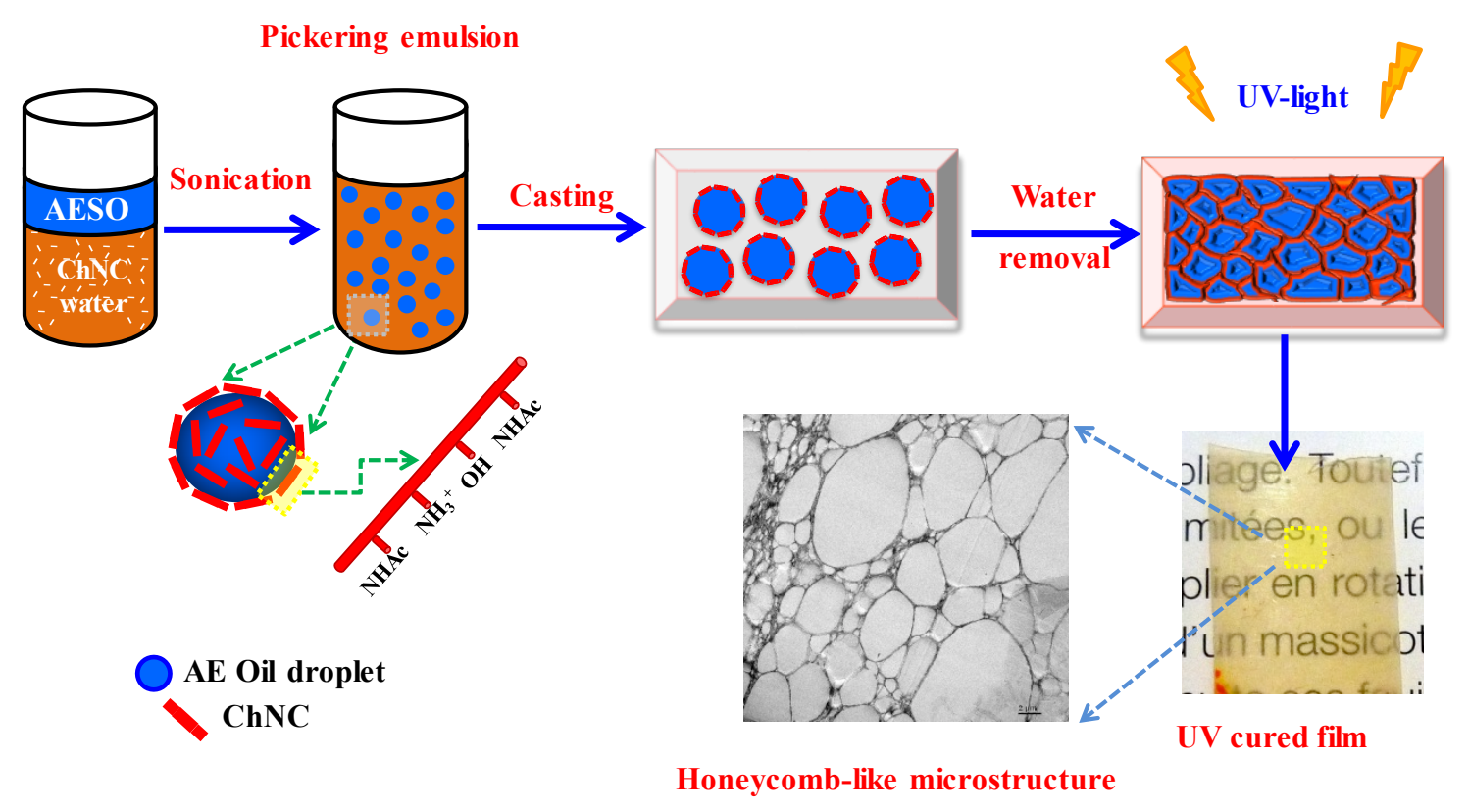

Published in: Biomacromolecules 22 (2021), 3780-3790

DOI: $10.1021 /$ acs.biomac.1c00612 


\begin{abstract}
Stable biobased waterborne Pickering dispersions of acrylated epoxidized soybean oil (AESO) were developed using chitin nanocrystals (ChNCs) as sole emulsifier without any additives. Thin AESO-ChNC nanocomposite films were produced by UV-curing thin-coated layers of the AESO emulsion after water evaporation. The kinetics of photopolymerization was assessed by monitoring the consumption of the AESO acrylate groups by infrared spectroscopy (FTIR). The

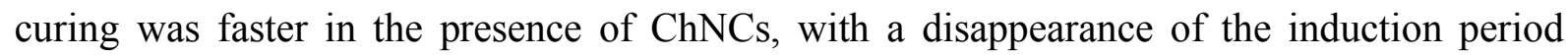
observed for neat AESO. The coating of AESO droplets with a thin layer of ChNCs was confirmed by scanning electron microscopy (SEM) observation. SEM and transmission electron microscopy (TEM) images revealed the honeycomb organization of the ChNCs inside the cured AESO-ChNC films. The mechanical, thermal and optical properties of the nanocomposite films were studied by dynamic mechanical analysis (DMA), tensile testing, differential scanning calorimetry (DSC) and transmittance measurement, as a function of ChNC content. The inclusion of ChNCs is strongly beneficial to increase the stiffness and strength of the cured films, without compromising its optical transparency. The ability of ChNCs to act as an emulsifier for AESO in replacement of synthetic surfactants and their strong reinforcing effect in UV-cured films offer new opportunities to produce waterborne stable dispersions from AESO for application in biobased coatings and adhesives.
\end{abstract}

Keywords: Chitin nanocrystals, Pickering emulsion, UV-curing, coating. 


\section{INTRODUCTION}

In recent years, driven by sustainability and environmental friendliness concerns, the use of biobased materials in coatings has received great attention to partially or totally substitute monomers, oligomers and binders, originating from petroleum resources. ${ }^{1}$ Among them, soybean oil (SO) is an important cost-effective precursor for a wide class of macromonomers for polymer materials and organic coatings. ${ }^{2}$ Thanks to its triglyceride structure and multiple double bonds in the backbone chains, many types of chemical reactions involving the ester and double bonds can be achieved, including transesterification, epoxidation, ozonolysis, oxidation, and epoxide ring-opening ${ }^{3}$ for hydroxyl functionalities.

Epoxidized soybean oil (ESO) is an industrial reactive oil used in a wide variety of applications. ${ }^{2}$ Acrylated epoxidized soybean oil (AESO) is produced via ring-opening of the epoxide groups of ESO with acrylic acid. It is widely used as a macromonomer alone or in association with other epoxy acrylate resins in UV-curing coatings, printing inks, adhesives, and composites. ${ }^{4}$ Thanks to its numerous advantages including low energy demand, low volatile organic compound (VOC) emission, low cost investment and fast curing even at ambient temperature, the UV-curing technology has attracted increasing interest from both industry and academia.

For many coating applications, volatile organic solvents are included in order to reduce the viscosity, facilitate applications and prevent surface coating defects. The switch to waterborne solvent free-coatings prepared by emulsification of a binder in water is meant to meet the environmental regulations and the growing consumer demand for more environmentally friendly products. $^{5}$ For emulsification requirements, the addition of a surfactant at an appropriate level, exceeding $5 \%$ of oil phase in some formulations, is necessary to ensure the long-term colloidal stability of the emulsion and prevent droplet coalescence by Ostwald ripening and flocculation. The presence of residual surfactant after film-formation and water removal might induce negative effects, such as increased water sensitivity, adhesion to the substrate, low brightness and scratch resistance. The possibility to get rid of surfactants in emulsions by substituting them with solid stabilizers can be envisaged, giving rise to the sonamed Pickering emulsions. In this class of emulsions, solid particles with capacity to adsorb at the oil/water interface or generate strong network encapsulating oil droplets can stabilize $\mathrm{O} / \mathrm{W}$ emulsion by providing a steric barrier, opposing droplets to coalesce and flocculate. Among the wide choice of solid particles used for the stabilization of Pickering emulsions, polysaccharide-based nanoparticles, such as cellulose nanofibrils (CNFs), cellulose nanocrystals (CNCs), starch nanocrystals (SNCs), chitin nanofibers (ChNFs) or chitin 
nanocrystals (ChNCs), have attracted great interest during the last decades, ${ }^{6}$ thanks to their non-toxicity, ${ }^{7}$ biodegradability, large specific surface, and a wide range of chemical surface modifications to tune wetting properties.

ChNCs are biobased needle-shaped nanoparticles, that can be extracted from many living organisms, including crustacean shells and fungal cell walls, through a controlled hydrolysis treatment to severe the less-organized regions and release the crystallites. The efficiency of ChNCs and ChNFs as Pickering stabilizers for oil-in-water $(\mathrm{O} / \mathrm{W})$ emulsions has been demonstrated in several works related to emulsions for food, ${ }^{8}$, nanocomposites, ${ }^{9}$, foams, ${ }^{10}$ and high-internal-phase (HIPE). ${ }^{11}$ However, by comparison with CNCs, the use of ChNCs as Pickering emulsifier was less studied despite their higher stabilizing efficiency. Moreover, most of the studies focused on the emulsion properties and less for the design of nanocomposites with improved properties and greener processing. ${ }^{12}$ The substitution of synthetic surfactants with ChNCs, taking advantage of their strong reinforcing properties, would open new opportunities to produce surfactant-free waterborne biobased coatings, inks, and adhesives.

In our previous work, we have shown that ChNCs could be used as an effective emulsifier for epoxidized soybean oil (ESO) and AESO thanks to their strong interaction with oil droplets through hydrogen bonding with epoxy and hydroxyl groups of the oil. ${ }^{13}$ Emulsions with longterm stability and mean droplet size lower than 1-2 $\mu \mathrm{m}$ could be generated by addition of ChNCs to an oil-water mixture at a content between 1.5 and $2 \mathrm{wt} \%$. In the present work, we continue our investigation about the usefulness of $\mathrm{O} / \mathrm{W}$ reactive emulsions stabilized by $\mathrm{ChNCs}$ as waterborne nanocomposite dispersions for UV-curing $1 \mathrm{~K}$ coating application. More specifically, our objective was to demonstrate the potential of waterborne UV-curable coatings based on AESO solely emulsified with ChNCs instead of synthetic surfactants. The microstructure of the UV-cured films was studied and the effect of ChNC content on the curing kinetics of the film, the thermal and mechanical properties of the film and its optical transparency, was investigated.

\section{EXPERIMENTAL SECTION}

\subsection{Materials}

Acrylated epoxidized soybean oil (AESO) containing 4000 ppm of monomethyl ether hydroquinone as an inhibitor, was a product from Arkema. This oil is in the form of a slightly viscous and light-colored liquid. Deionized water was used for all emulsifications and treatment processes. Chitin from crab shells was obtained from, and hydrochloric acid (37 vol\%) were products from Sigma Aldrich. Irgacure $184 \mathrm{UV}$-initiator was kindly provided by Ciba. 


\subsection{ChNC preparation}

ChNCs were prepared according to the protocol described in our previous work. ${ }^{13}$ In brief, $4 \mathrm{~g}$ of chitin was added to $4 \mathrm{M} \mathrm{HCl}$ solution and maintained under stirring for $1.5 \mathrm{~h}$ at $90{ }^{\circ} \mathrm{C}$. The ChNCs were recovered by centrifugation at $8000 \mathrm{rpm}$ and purified by dialysis and successive washing-centrifugation treatment. ${ }^{14} \mathrm{ChNCs}$ stock suspension at $4 \%$ solid content was sonicated during $1 \mathrm{~min}$ at a 60\% amplitude (Sonics Vibracel Model CV33) and used in the emulsion preparation. The degree of deacetylation (DD) was determined by conductometric titration according to the method described in our previous work. ${ }^{12}$

\subsection{Preparation of the Pickering emulsions}

Three grams of AESO were mixed with $15 \mathrm{~mL}$ of $\mathrm{ChNC}$ aqueous suspension during 2 min by vortexing and sonicated during $1 \mathrm{~min}$ at a $50 \%$ amplitude (Sonics Vibracel Model CV33) in a cold-water bath.

\subsection{Nanocomposite film preparation}

Nanocomposite films were prepared by coating the AESO emulsified by ChNCs and containing a photoiniator ( $3 \mathrm{wt} \%$ Irgacure 184 , based on AESO) on a $10 \times 10 \mathrm{~cm}^{2}$ glass panel using a calibrated spreader to form a film with the thickness of $800 \mu \mathrm{m}$. After drying the film at room temperature for $4 \mathrm{~h}$, it was cured at room temperature for 5 min using a $200 \mathrm{~W}$ UVAHAND 100 Hönle medium pressure lamp. The different steps involved in the preparation of the UV-cured nanocomposite film are illustrated in Scheme 1. In the following, the films will be referred to as AESO-ChNCn, $\mathrm{n}$ being the wt $\%$ of ChNCs with respect to AESO phase.

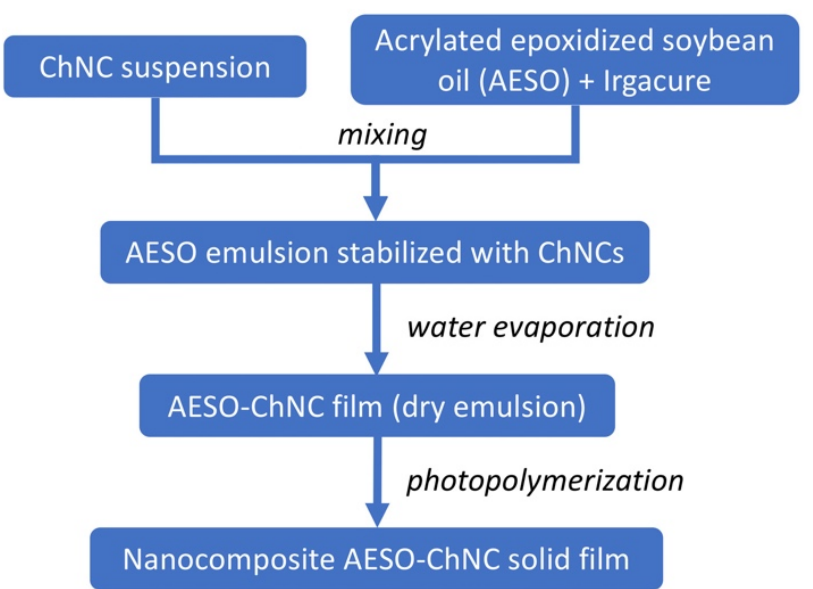

Scheme 1. Preparation method of AESO-ChNC thin films by Pickering emulsion and photocuring. 


\subsection{Photopolymerization kinetics by FTIR}

The photopolymerization kinetics of AESO was determined by FTIR in transmission mode using a Perkin Elmer Spectrum Two L160000A spectrometer and a liquid cell with controlled path. The emulsion was spread over a ZnSe windows, dried, and irradiated with UV light via a fiber optic source (UVET-UV LED spot curing) with an output intensity of $10 \mathrm{~W} \mathrm{~cm}^{-2}$. The FTIR spectrum was recorded intermittently (one spectrum was recorded every $0.4 \mathrm{~s}$ with a resolution of $4 \mathrm{~cm}^{-1}$ ) in absorbance mode after subtraction of the background spectrum. The acrylate conversion was calculated by the absorption decrease of the acrylate double bonds at $810 \mathrm{~cm}^{-1}$ as follows:

$$
\text { conversion }(\%)=\frac{\left(A_{C=C}^{0}-A_{C=C}^{t}\right)}{A_{C=C}^{0}} \times 100
$$

where $A_{C=C}^{0}$ and $A_{C=C}^{t}$ are the absorbance of the $\mathrm{C}=\mathrm{C}$ band at $810 \mathrm{~cm}^{-1}$ before exposure to UV light and at time $t$, respectively.

\subsection{Differential scanning calorimetry (DSC)}

DSC thermograms were recorded using a Perkin-Elmer Pyris Diamond instrument in a temperature range from -80 to $100{ }^{\circ} \mathrm{C}$, under nitrogen gas at a heating rate of $10{ }^{\circ} \mathrm{C} \mathrm{min}^{-1}$, using air as reference.

\subsection{Dynamic mechanical analysis (DMA)}

DMA measurements were conducted in tension mode using a Perkin-Elmer Pyris Diamond instrument. The storage modulus $(E)$ and the loss factor $\tan \delta$ were measured at a frequency of $1 \mathrm{~Hz}$ in a temperature range of -50 to $125^{\circ} \mathrm{C}$ at a heating rate of $3{ }^{\circ} \mathrm{C} \mathrm{min}-1$.

\subsection{Tensile tests}

Rectangular films $(40 \mathrm{~cm} \times 0.5 \mathrm{~cm} \times 200 \mu \mathrm{m})$ were analyzed in tensile mode using an Instron Universal Testing Machine with a load cell of $100 \mathrm{~N}$ working at a strain rate of $10 \mathrm{~mm} \mathrm{~min}^{-1}$, at $25{ }^{\circ} \mathrm{C}$ and $50 \%$ relative humidity. Three tests were carried out for each composition.

\subsection{Transmittance measurement}

The transmittance was measured in the visible range using the UV-Vis Lambda 35 Spectrometer (Perkin Elmer, USA). To avoid the influence of the variation of the film thickness, the film transmittance was normalized to a $200 \mu \mathrm{m}$-thick film using the Beer-Lambert law. 


\subsection{Swelling and solubility in toluene}

Samples of films were immersed in toluene and left under magnetic stirring for $48 \mathrm{~h}$. Then the sample was removed, wiped with filter paper and weighed. The swelling in toluene was calculated from the difference in weight of the dry samples before $\left(m_{0}\right)$, after swelling $(m)$ and drying $\left(m_{f}\right)$ at $60{ }^{\circ} \mathrm{C}$ during $12 \mathrm{~h}$, using the following equations:

$$
\begin{aligned}
& \text { swelling degree }(\%)=100 \times \frac{m-m_{0}}{m_{0}} \\
& \text { dissolved fraction }(\%)=100 \times \frac{m_{0}-m_{f}}{m_{f}}
\end{aligned}
$$

\subsection{Transmission electron microscopy (TEM)}

A droplet of a dilute ChNC aqueous suspension ( $c a$. $0.001 \mathrm{wt} \%$ ) was deposited onto glowdischarged carbon-coated copper grids and negatively stained with $2 \mathrm{wt} \%$ uranyl acetate. Ultrathin sections $(c a .70 \mathrm{~nm})$ of the UV-cured AESO-ChNC films were cut with a diamond knife at $-60^{\circ} \mathrm{C}$ using the EMFC7 cryomodule of a Leica UC6 ultramicrotome. All specimens were observed at room temperature with a JEOL JEM-2100 Plus microscope operating at $200 \mathrm{kV}$ and equipped with a Gatan Rio 16 digital camera.

\subsection{Scanning electron microscopy (SEM)}

As described in a previous article, ${ }^{14}$ the UV-initiator ( $1 \%$ ) was incorporated in the AESO oil that was emulsified in the presence of ChNCs. The Pickering emulsion was irradiated with UV light to induce crosslinking in the oil, rigidify the droplets, and prevent the flowing of the oil upon drying. A drop of the emulsion was deposited on carbon tape and allowed to dry. After UV-curing, the films prepared from the AESO-ChNC Pickering emulsions were fractured in liquid nitrogen. The fragments were fixed on metallic stubs. All specimens were coated with $\mathrm{Au} / \mathrm{Pd}$ in a Baltec MED-020 sputter coater and observed in secondary electron mode in Thermo Scientific Quanta 250 and Zeiss Gemini SEM 500 microscopes equipped with field emission guns and operating at 2.5 or $3 \mathrm{kV}$.

\section{RESULTS AND DISCUSSION}

\subsection{Morphology and size of the ChNCs}

As seen in the TEM image of Figure 1A, ChNCs were polydisperse rodlike objects with a length typically ranging from 150 to $1500 \mathrm{~nm}$ (number-average mean length: $628 \pm 264 \mathrm{~nm}$ ) and a width between 10 and $60 \mathrm{~nm}$. The particles were composed of a few laterally-associated elementary crystallites that were not separated during the preparation process. 

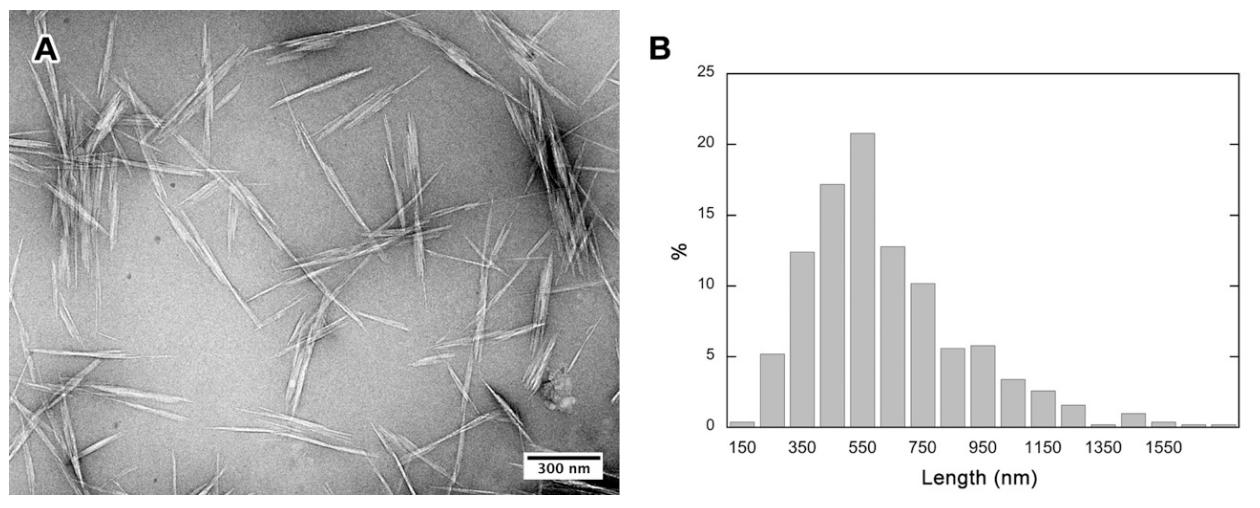

Figure 1. (A) TEM image of a negatively stained preparation of ChNCs, and (B) length distribution histogram determined from the TEM images for a population of 500 particles.

\subsection{Morphology of the UV-cured AESO-ChNC Pickering emulsion}

The encapsulation of AESO by ChNCs was confirmed by SEM observation of an AESO emulsified with $8 \mathrm{wt} \% \mathrm{ChNCs}$ and exposed to UV-light prior to sample preparation (Figure 2). The images clearly revealed polydisperse spheroidal or elongated droplets coated with ChNCs, which indicates the effective emulsifying aptitude of ChNCs to stabilize the AESO droplets, as was discussed in depth in our previous work. ${ }^{13}$ The equilibrium shape of the droplets likely depends on the diameter of the droplets (i.e. the curvature of the surface) with respect to the length and relative rigidity of the ChNCs, and the nature of the interaction between both constituents. Indeed, covering the surface of a sphere with rigid rods is a complex topological problem and the SEM images clearly show that only the larger particles exhibit a spherical shape with a surface covered by a fairly homogeneous layer of ChNCs.
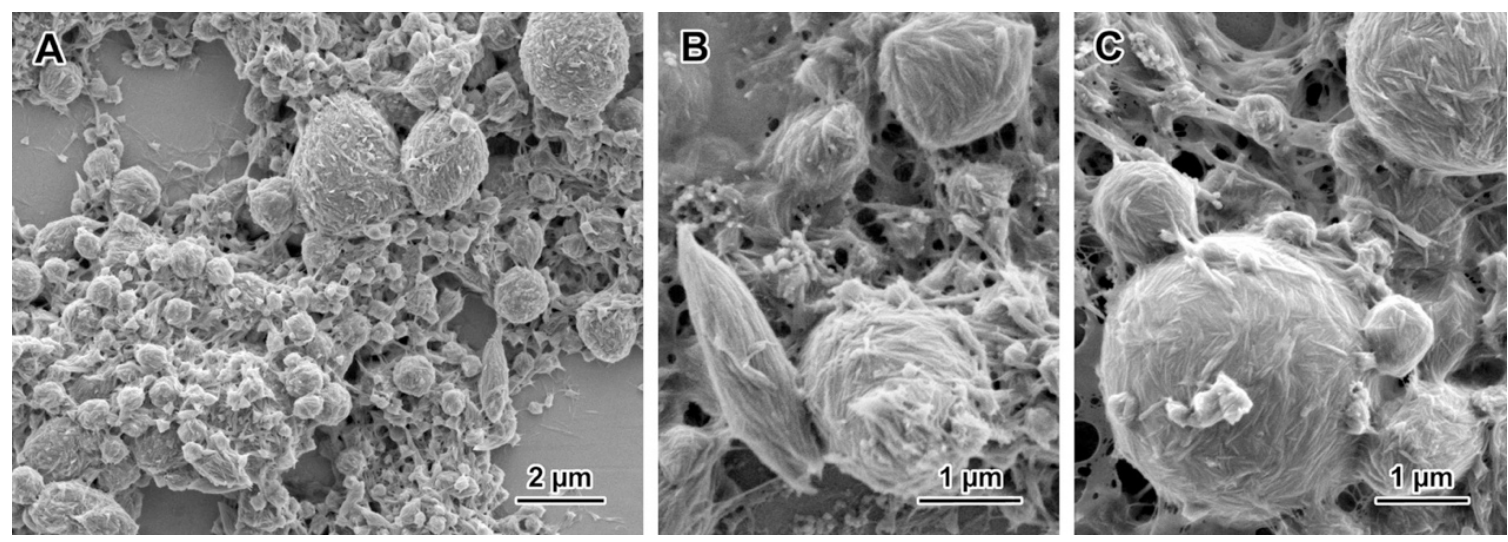

Figure 2. (A-C) Secondary electron SEM images of AESO emulsified with $8 \mathrm{wt} \% \mathrm{ChNCs}$ in the presence of $1 \mathrm{wt} \%$ Irgacure 184 photoinitiator. Prior to sample preparation, the emulsion was exposed to UV light for 1 min to induce crosslinking in the oil droplets. 


\subsection{Kinetics of $U V$-curing of the films}

The kinetics of UV-curing of AESO films filled different amounts of ChNCs were studied by FTIR by monitoring the disappearance of the acrylic bonds of AESO in situ. Given the rapidity of the photopolymerization reaction, with complete curing within 100-200 s, a thin film of about $20 \mu \mathrm{m}$ was spread over a $\mathrm{CsCl}$ window, dried and exposed to UV irradiation via a fiber optic source and the FTIR spectra were recorded at intermittent times. The conversion of the acrylate double bond was evaluated by monitoring the absorbance of the $\mathrm{C}=\mathrm{C}$ band at about $810 \mathrm{~cm}^{-} 1$, which is attributed to the out-of-plane deformation of the $\mathrm{C}=\mathrm{C}$ bond of the acrylate groups. This band is often used for the UV-curing of AESO as it is less affected by the adjacent band. Examples of FTIR spectra collected during the curing of AESO and AESO-ChNC films are shown in Figures 3A,C from which the kinetics of consumption of acrylic function was established (Figure 3D). ${ }^{15}$ The curing rate of AESO was quite fast with more than $90 \%$ of the acrylate functions being consumed within $60 \mathrm{~s}$. However, the final conversion was not total and seems to be levelled off at around $90 \%$, indicating that not all of the acrylate groups were consumed during the photocuring process, which agrees with literature data. ${ }^{16}$ In the presence of ChNCs, two evolutions can be seen. The first one is the rapid initial rate with more than $50 \%$ conversion achieved after about $15 \mathrm{~s}$ of irradiation. The second evolution is the decrease in the final conversion limit, attaining about 86 and $80 \%$ in the presence of 4 and $8 \mathrm{wt} \% \mathrm{ChNCs}$. In fact, the lower initial conversion rate for neat AESO is due to an induction period of about 15 $\mathrm{s}$, which disappeared in the presence of ChNCs. In the UV-curing process, an induction period during photopolymerization has often been reported in the literature ${ }^{17}$ and was explained by the diffusion of oxygen at the film surface that inhibits the polymerization by trapping the radical generated from the UV-decomposition of the initiator. When the total dissolved oxygen is consumed, polymerization is triggered and the curing process is rapidly achieved. In the present study, the disappearance of the induction period may be due to the presence of a thin ChNCs layer encapsulating AESO, that act as a barrier against the diffusion of oxygen inside the oil phase. The strong barrier property of ChNC-filled thin films against oxygen has been demonstrated in several papers. ${ }^{18,19}$ 

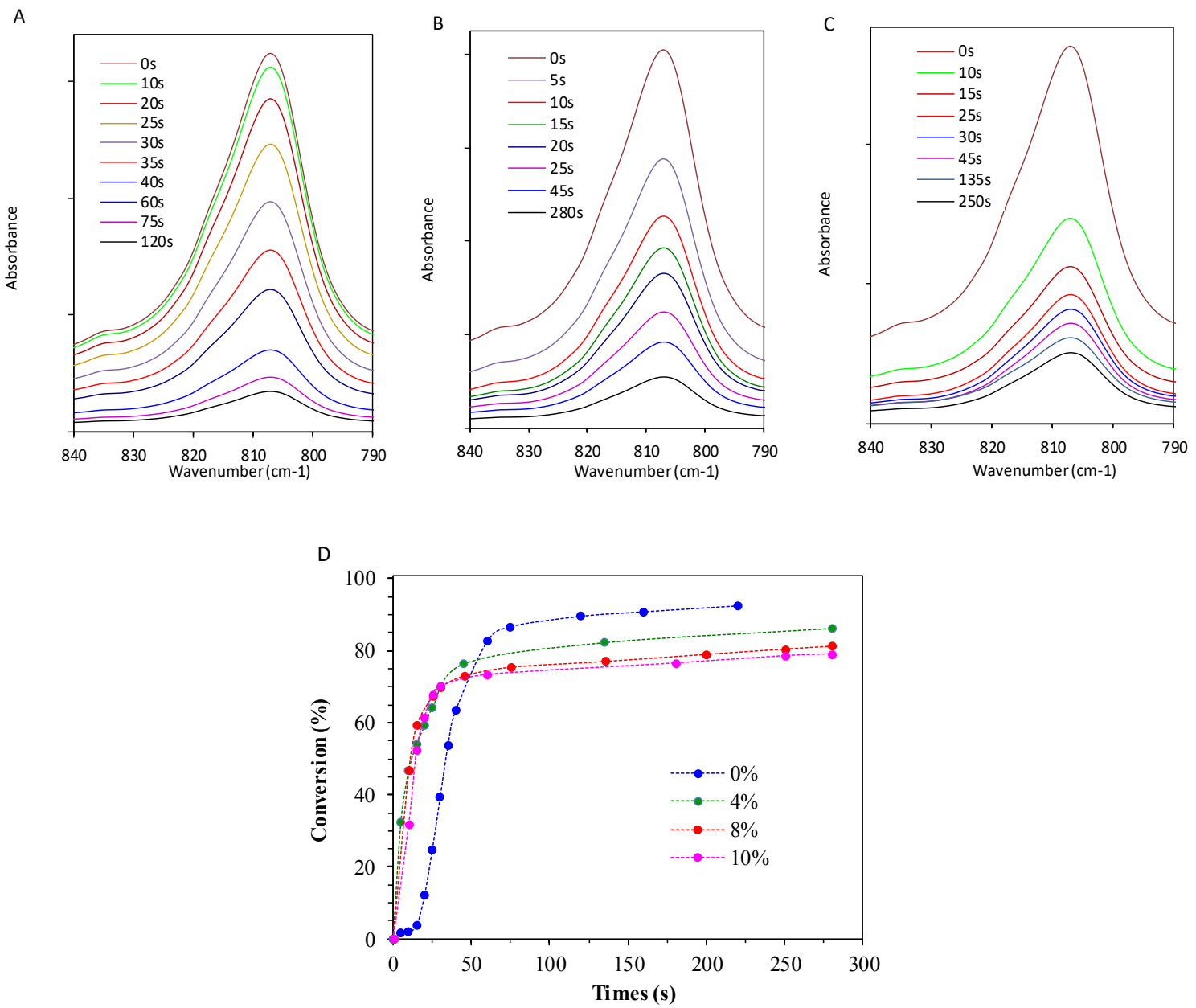

Figure 3. Variation of the acrylate stretching band at $1610-1640 \mathrm{~cm}^{-1}$ as a function of time, after subtraction of the uncured AESO reference spectrum: (A) neat AESO, (B) AESO-ChNC4, and (C) AESO-ChNC8; (D) conversion of acrylate as a function of $\mathrm{ChNC}$ content determined by FTIR. 

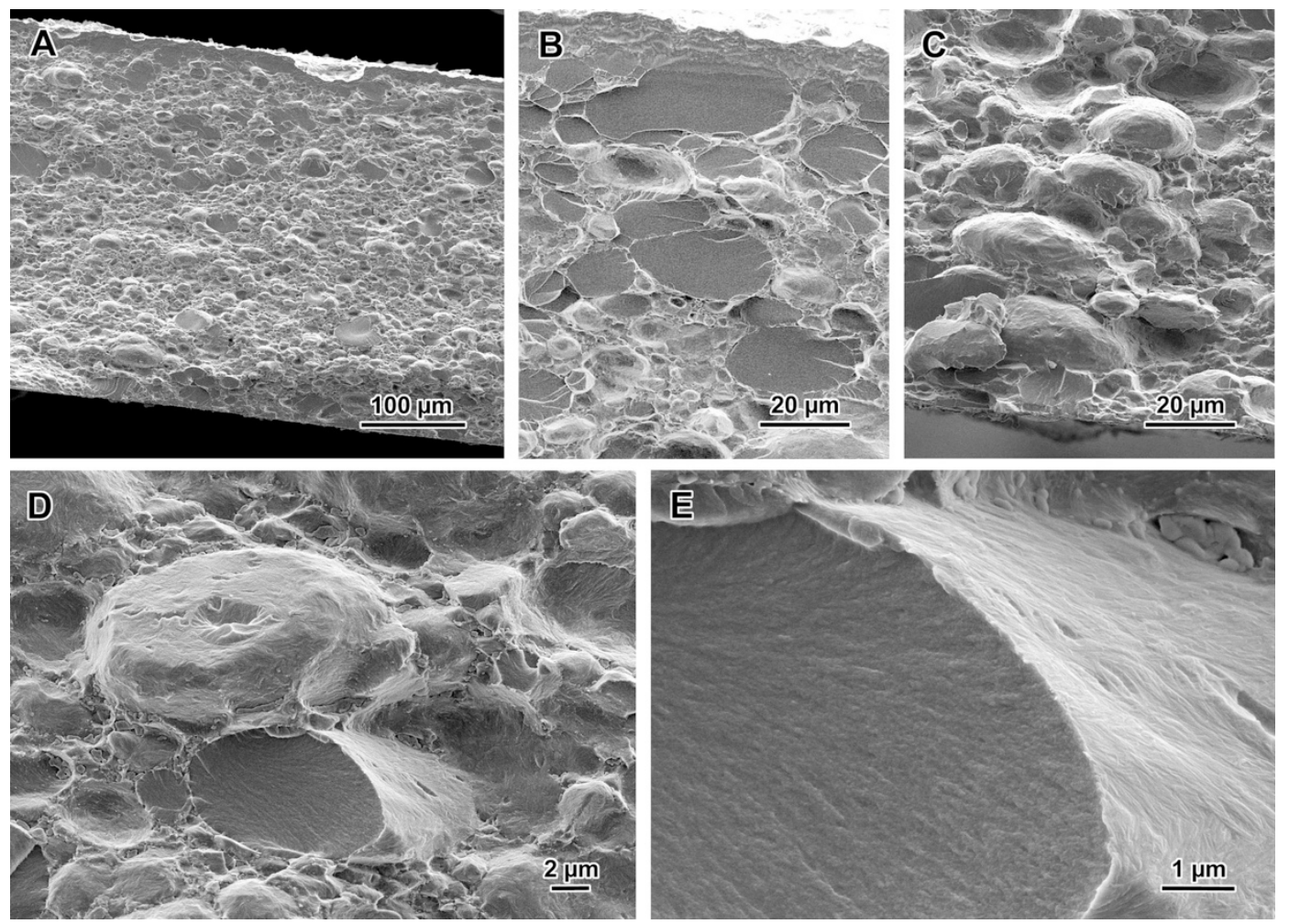

Figure 4. Secondary electron SEM images of the cross-section of a UV-cured AESO-ChNC4 film fractured in liquid nitrogen.
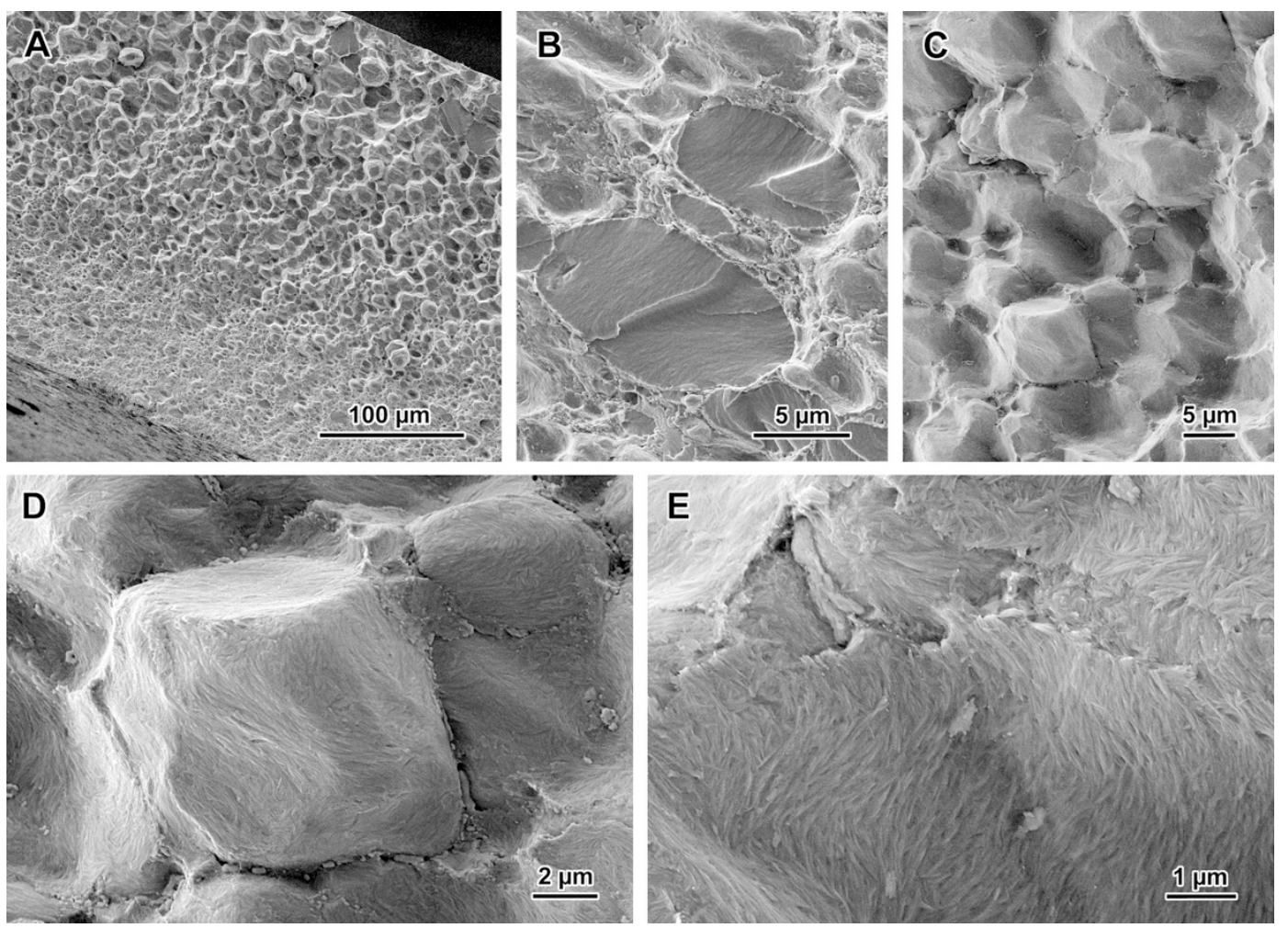

Figure 5. Secondary electron SEM images of the cross-section of a UV-cured AESO-ChNC10 film fractured in liquid nitrogen. 


\subsection{Morphology of the UV-cured films}

AESO-ChNC films produced by casting AESO-ChNC emulsions and UV-curing were observed in cross-section by SEM after fracture in liquid nitrogen. The fracture of the neat AESO film was sharp (Supporting Information Figure S1A) and the surface was rather smooth without specific features (Figure S1B). The cross-section images of the films prepared from emulsions stabilized with 4,8 and $10 \mathrm{wt} \% \mathrm{ChNCs}$ revealed a cellular microstructure (Figures 4A, S2A and 5A, respectively) in which AESO droplets adopted a polyhedral shape due to the compression during thin-film forming and subsequent air drying. Higher magnification images (Figures 4B,C, 5B,C and S2B) showed that the material was fractured in two ways: either the cells were broken in the middle and the flat topography was similar to that of the neat AESO film (Figures S1B, 4B,D,E and 5B), or the fracture occurred at the interface between polygonal cells (Figures 4C,D, 5C,D and S2B). Layers of densely packed ChNCs could then be seen at the surface of the cells (Figures $4 \mathbf{E}$ and $\mathbf{5 E}$ ).

TEM images of an ultrathin cryosection of the AESO-ChNC10 film confirmed the irregular honeycomb distribution of ChNCs in the AESO matrix (Figures 6 and S3). In the Pickering emulsion, the ChNCs were only located at the surface of the polydisperse AESO droplets, which clearly prevented the coalescence of AESO droplets upon water evaporation and UV-irradiation. The ChNC cell wall thickness typically ranged from 50 to $200 \mathrm{~nm}$, except between the smaller cells around which the ChNC concentration was higher and the wall thicker. Similar honeycomb-like microstructures have previously been reported in films prepared by casting acrylic latexes blended with cationic $\mathrm{CNCs}^{20}$ and poly(styrene- $b$-butyl acrylate) particles coated with Laponite platelets. ${ }^{21}$
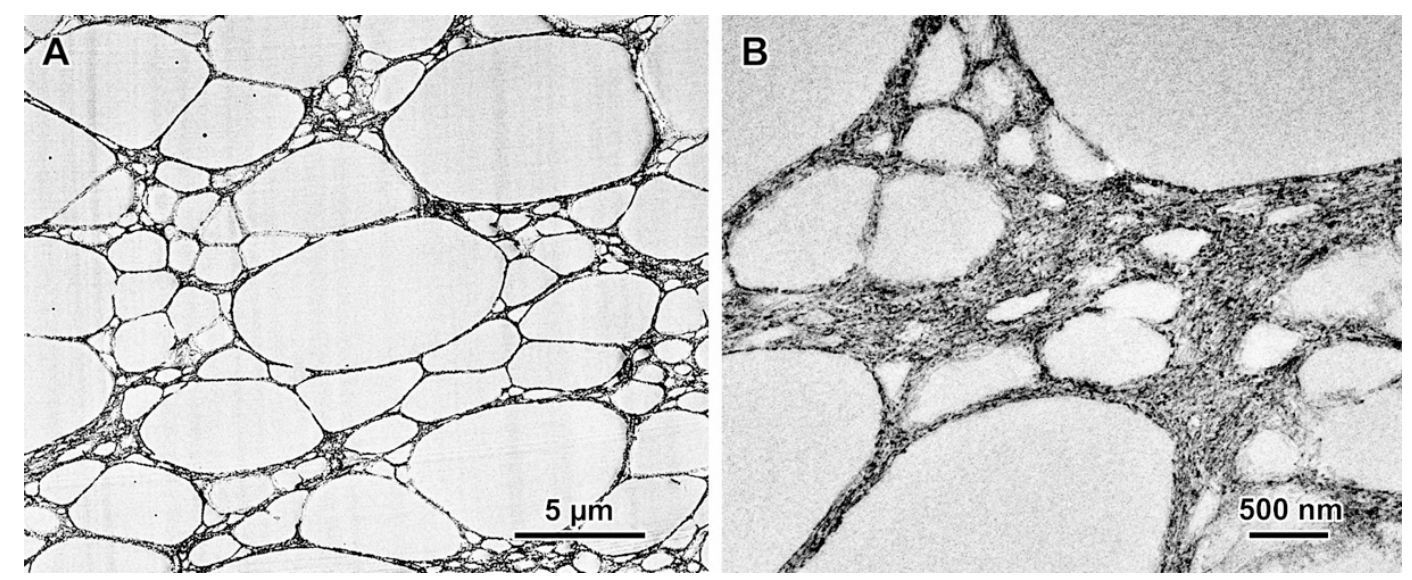

Figure 6. (A,B) Low-dose bright-field TEM images of the ultrathin cryosection of a UV-cured AESO-ChCN10 film. The cell walls appear as dark regions due to the crystalline ChNCs that generate a Bragg diffraction contrast. 
When comparing the morphology of the film at 4, 8 and $10 \%$ ChNC contents, we can note a decrease in the mean size of the honeycomb cellule with increasing ChNC content, especially at 8 and $10 \%$ content. When measured from the SEM images of cryofractured films, the size distribution of the cells in the cured film (Figure S4) was found to be in the 5-40 $\mu \mathrm{m}, 4-20 \mu \mathrm{m}$ and 2-18 $\mu \mathrm{m}$ ranges, respectively. This follows the trend previously observed for neat AESO Pickering emulsions stabilized by $\mathrm{ChNCs},{ }^{14}$ where smaller droplet distributions were obtained with increasing ChNC content, as a higher number of ChNCs was available to stabilize the AESO droplets. However, upon drying, as water evaporates, droplets got tightly packed under the effect of the capillary forces which is inversely proportional to the diameter of the droplets and proportional to the surface tension. Confinement drove the droplets to form polyhedral cells, and droplets being not fully covered by ChNCs aggregated to achieve a higher coverage degree and resist the capillary pressure. This phenomenon would occur mainly at ChNC contents lower than $10 \mathrm{wt} \%$ (with respect to AESO content), which explains the wide size distribution in the cellular structure of cured AESO at $4 \mathrm{wt} \% \mathrm{ChNCs}$ (Figure 4). The end result of the drying stage is an irregular honeycomb structure composed of AESO droplets fully encapsulated with ChNCs with a macroscopic homogeneous film without any residual water. Upon exposition to UV-light, the rapid curing occurred within less than 1 min, making the AESO-ChNC film rigid and transparent.

The SEM image of the top surface of the cured AESO-ChNC10 film shows a dense layer of ChNCs (Figure 7) likely formed upon water removal prior to the exposition to the UV-light. Along with the cellular distribution of ChNCs in the film, this surface layer likely contributes to the barrier effect of ChNCs against oxygen diffusion.

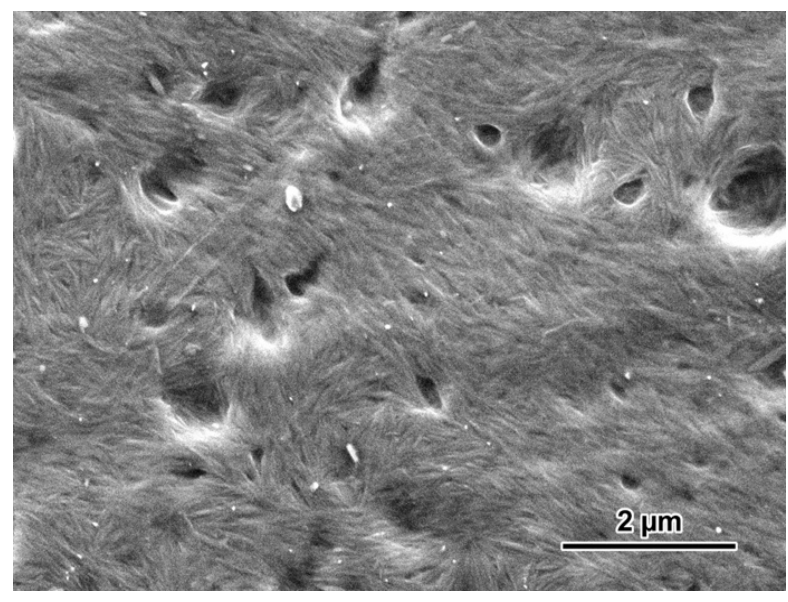

Figure 7. SEM image of the top surface of a UV-cured AESO-ChNC10 film. 

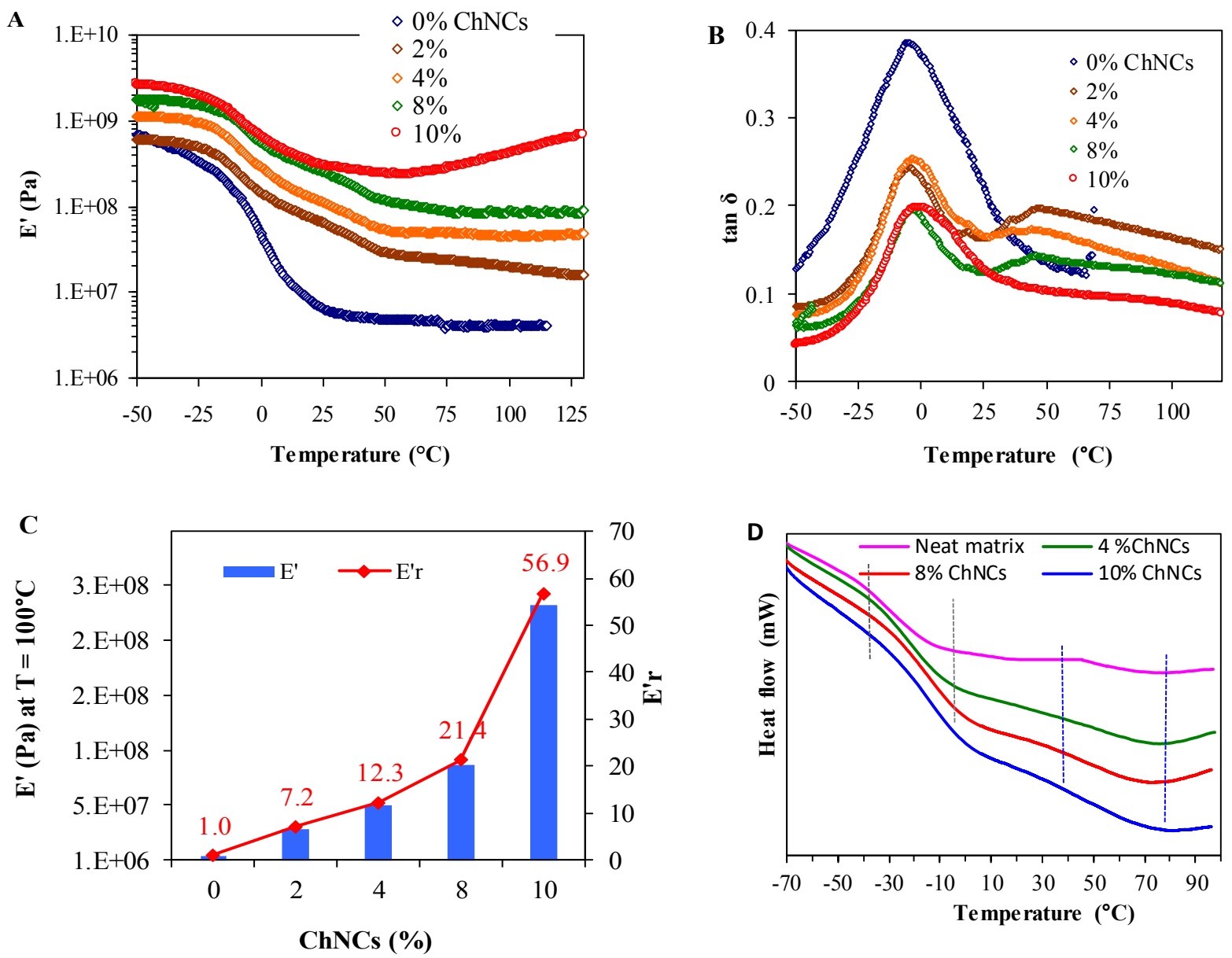

Figure 8. (A) Variation of storage modulus $E^{\prime}$ and (B) $\tan \delta$ with temperature for UV-cured AESO-ChNC nanocomposite films at different ChNC contents; (C) plot of $E_{r}^{\prime}=E_{c}^{\prime} / E_{m}^{\prime} v s$. $\mathrm{ChNC}$ content for the nanocomposite films at $70^{\circ} \mathrm{C}$; (D) DSC thermograms of AESO-ChNC films.

\subsection{Mechanical and thermal properties}

One of the major benefits of the inclusion of nanoscale fibrillar biobased particles is their strong positive influence on the mechanical performance of soft polymer film. To investigate the effect of the inclusion of ChNCs on the mechanical and stiffness properties of AESO-ChNC composite films after curing, DMA and stress-strain analysis were carried out (Figures 8 and 9). The temperature dependency of the storage modulus $\left(E^{\prime}\right)$ of the nanocomposite films with different ChNC contents is shown in Figure 8A. For the unfilled UV-cured AESO film, the $E^{\prime}$ plot showed the typical behavior of a crosslinked polymer, as attested by the lack of flowing region. A clear glass-transition accompanied by more than a two-decade decrease of $E^{\prime}$ is observed between -20 to $50{ }^{\circ} \mathrm{C}$, giving rise to a maximum in the $\tan \delta$ trace around $-5{ }^{\circ} \mathrm{C}$ (Figure 8B). In nanocomposite films containing ChNCs, an upward shift of the $E^{\prime}$ trace was observed, indicating an increase in the film stiffness in the glassy and rubbery domains. The effect was much more pronounced in the rubbery domain, with an increment in the modulus 
$E_{r}=E_{c}^{\prime} / E_{m}^{\prime}$ (with $E_{c}^{\prime}$ and $E_{m}^{\prime}$ are the storage modulus of the composite and unfilled matrix respectively measured in the rubbery region taken here at $70{ }^{\circ} \mathrm{C}$ ), of about 21 and 58 , in the presence of 8 and $10 \mathrm{wt} \% \mathrm{ChNCs}$, respectively (Figure 8C). This significant increase of $E^{\prime}$ was expected given the nanosize and the rodlike shape of ChNCs, along with their aptitude to set up a network ${ }^{22}$ held by hydrogen bonding. The reinforcement mechanism will be discussed in the following.

Another effect accompanying the addition of ChNCs is the emergence of a new relaxation, giving rise to a maximum in the tan $\delta$ plot around $35-45^{\circ} \mathrm{C}$, and to a second inflection point in the $E^{\prime}$ plot. This second transition is likely associated with the matrix in the near vicinity of ChNCs, where the physical interaction through hydrogen bonding between amide and amino groups of ChNC surface and hydroxyl group of AESO would induce a restriction in the mobility of the chains in contact with ChNCs. The possibility of a chemical linkage between AESO chains and ChNCs, through transfer or termination reaction involving a macroradical and $\mathrm{NH}_{2}$, hydroxyl or amide group of ChNCs might also be considered. ${ }^{23}$ The hypothesis of the emergence of a new transition for cured AESO-ChNC films was supported by DSC data (Figure 8D). The thermogram of cured neat AESO films showed a single $\mathrm{T}_{\mathrm{g}}$ around $-20{ }^{\circ} \mathrm{C}$ (position of the inflection point), while a second transition at a higher temperature emerged in the ChNC-containing films at around $50^{\circ} \mathrm{C}$.

The stress-strain profiles of cured AESO films at different ChNC contents are presented in Figure 9A and the corresponding tensile modulus $(E)$ and strength $(\sigma)$ are presented in Figure 9B. By comparison with the neat AESO film, the tensile strength and modulus of the composites were enhanced by the inclusion of ChNCs, as expected, while the strain at break notably decreased. This means that the cured AESO film containing ChNCs was tougher and more resistant. The magnitude of the effect was proportional to the $\mathrm{ChNC}$ content.

In an attempt to identify origin of the reinforcing effect induced by the addition of ChNCs, the experimental data were fitted with the percolation and Halpin-Tsai $(\mathrm{H}-\mathrm{T})$ models. The percolation model has been widely adopted for waterborne polymer dispersions and nanocomposites containing cellulose nanocrystals (CNCs). The significant increase in the composite stiffness is assumed to be related to the setting of a percolated network held by hydrogen bonding when the nanocrystal content is above a critical threshold. On the basis of this concept, the relative elastic tensile modulus $E_{r}$ of the composite can be expressed by the following equation as a function of $\psi, \phi$ and $b$ are the volume fraction of the percolating network, the total volume fraction of the nanofiller and the critical exponent, respectively: 


$$
E_{r}=\frac{E_{c}}{E_{m}}=\frac{(1-2 \psi+\psi \phi) E_{s}+(1-\phi) \psi E_{m}}{(1-\phi) E_{m}+(\phi-\psi) E_{s}}
$$

Where $E_{c}, E_{s}$ and $E_{m}$ are the moduli of the composite, ChNC network and the matrix, respectively. $E_{s}$, which differs from that of isolated nanocrystals, was estimated from the DMA analysis of thin films prepared by drying a pure $\mathrm{ChNC}$ suspension, and was found to be around $7 \mathrm{GPa}$. In addition,

$$
\psi=0 \text { when } \phi<\phi_{p} \text { and } \psi=\phi\left(\frac{\phi-\phi_{p}}{1-\phi_{p}}\right)^{b} \text { when } \phi \geq \phi_{p}
$$

and $b$ is equal to 0.4 for a $3 \mathrm{D}$ network.

The percolation threshold can be estimated by the following formula: ${ }^{24}$

$$
\phi_{p}=\frac{0.7}{L / d}
$$

Another semi-empirical model widely used to fit the modulus of aligned and randomly oriented composites is the $\mathrm{H}-\mathrm{T}$ model which assumes an effective interface between the matrix without taking fiber-fiber interactions into account. According to this model, that was successfully used for polymer nanocomposites filled with clay nanofillers, ${ }^{25}$ Young's moduli of the composite and the matrix, $E_{c}$ and $E_{m}$, respectively, are related by the expression:

$$
E_{r}=\frac{E_{c}}{E_{m}}=\frac{3}{8}\left(\frac{1+\zeta \eta_{L} \phi}{1-\eta_{L} \phi}\right)+\frac{5}{8}\left(\frac{1+2 \eta_{T} \phi}{1-\eta_{T} \phi}\right)
$$

$\zeta$ is a shape factor that depends on the filler geometry and loading direction. $\eta$ and $\zeta$ are given by:

$\eta_{L}=\frac{\left(\frac{E_{f}}{E_{m}}\right)-1}{\left(\frac{E_{f}}{E_{m}}\right)+\zeta} \quad, \quad \eta_{T}=\frac{\left(\frac{E_{f}}{E_{m}}\right)-1}{\left(\frac{E_{f}}{E_{m}}\right)+2} \quad$ and $\quad \zeta=2 \frac{L}{d}$

where $E_{f}$ and $E_{m}$ are the Young modulus of the filler and matrix, respectively.

The percolation model was plotted for two $L / d$ aspect ratios to take account of the large distribution in the length and width of ChNCs, using the following data for ChNCs: $E_{f}=150$ $\mathrm{GPa},{ }^{26} E_{r}=7 \mathrm{GPa}, L$ ranging from $200-800 \mathrm{~nm}$ and $d$ from $20-30 \mathrm{~nm}$.

As shown in Figure 8C, presenting the relative modulus $E_{r}=E_{c} / E_{m}$ (with $E_{c}$ and $E_{m}$ are the moduli of the composite and unfilled matrix, respectively), both the percolation and H-T models failed to properly fit the experimental data. The increment in modulus of the nanocomposite was much higher than that estimated on the basis of the H-T model but lower than that given by the percolation model. In fact, the H-T model was suitable in predicting the modulus of reinforcing particles with a variety of shapes in randomly oriented composites where the filler is well dispersed within the matrix, without any interaction among the reinforcement. ${ }^{24}$ Presently, the interaction between ChNCs through hydrogen bonding and the formation of a network may account for the higher modulus of the composite in comparison with the H-T 
model. However, the unsuitability of the percolation model in AESO-ChNC nanocomposites was unexpected, considering that this model properly predicted the stiffness of the nanocomposite based on biobased nanocrystals such as $\mathrm{CNC}$ and ChNC. ${ }^{27}$ Different reasons might justify this divergence: (i) the effective attachment of the ChNCs to the polymer matrix through hydrogen bonding without excluding a chemical grafting, (ii) the packing of ChNCs in a parallel fashion, (iii) the presence of the $\mathrm{N}$-acetyl groups of the ChNCs that reduce the magnitude of interaction through hydrogen bonding, and (iv) the cellular distribution of ChNC in the cured AESO films. The first two effects would disrupt the setting of a percolating network by limiting the interaction between neighboring ChNCs. Regarding the third case, indeed, the DD of the ChNCs was $9.3 \%$, which means that about $90 \%$ of the N-acetyl groups were not hydrolyzed. However, we assumed that this effect was limited given the high modulus of the pure ChNC film (7 GPa).
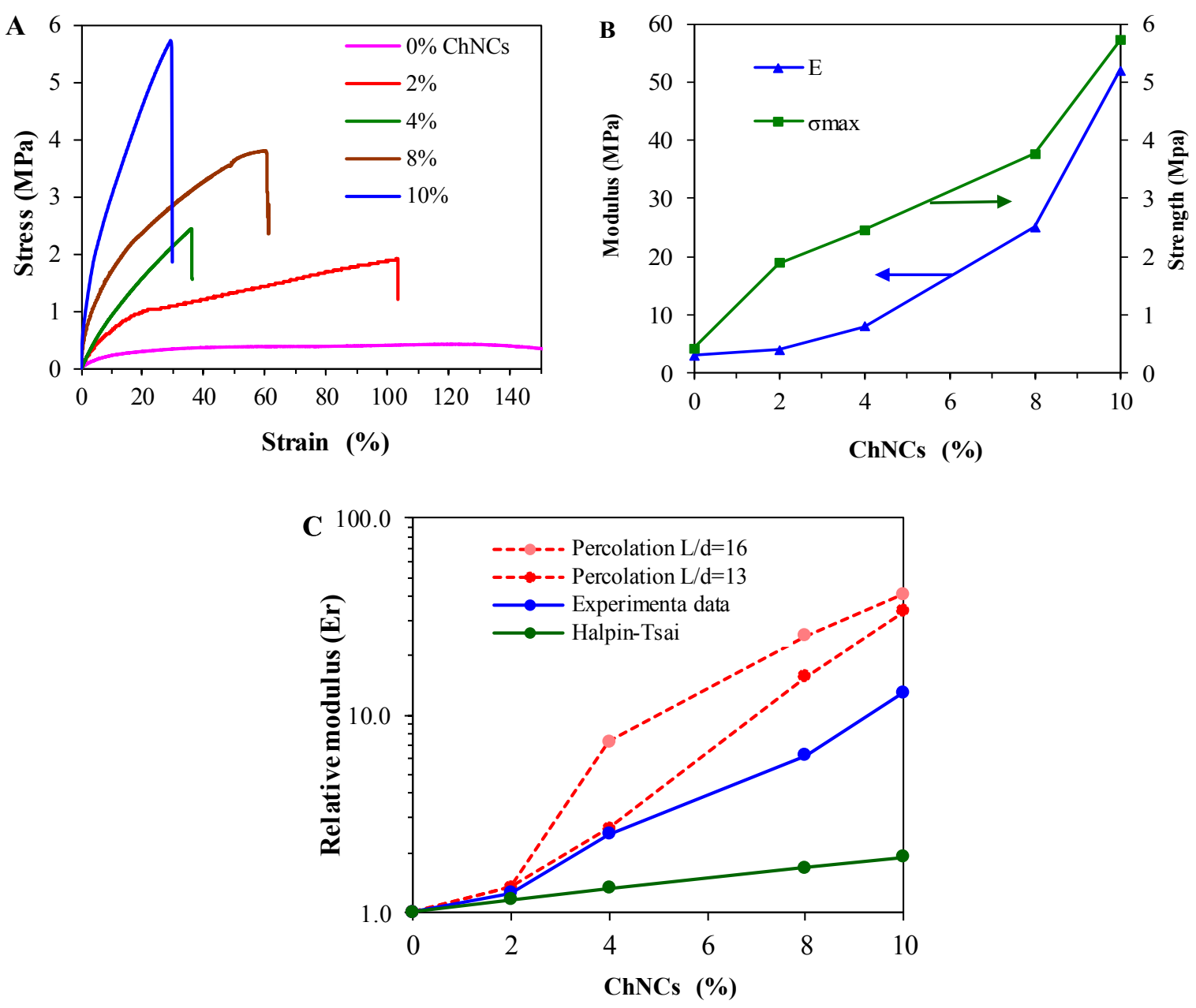

Figure 9. (A) Stress-strain curves of cured AESO-ChNC films, and (B) the tensile strength and modulus at different $\mathrm{ChNC}$ content; (C) $E_{r}$ (from tensile test) vs ChNC loading, comparison between the experimental data and predicted data from the percolation and Halpin-Tsai models. 
The honeycomb-like microstructure of the AESO-ChNC films might explain the particular evolution of their stiffness with $\mathrm{ChNC}$ content. Materials with a cellular structure are frequently encountered in nature including wood, cork, plant parenchyma and bones. ${ }^{28}$ Modelling these structures is complex and numerous parameters must be considered such as shape and size distribution of the cells, wall thickness and surface, and intrinsic modulus of cell walls and matrices. Further work is in progress to see how such models can be applied to our materials.

Given the low $\mathrm{T}_{\mathrm{g}}$ of the uncured neat AESO (around $-20^{\circ} \mathrm{C}$ ) along with the low modulus of the film at room temperature (around $20^{\circ} \mathrm{C}$ ), pure AESO in UV-coating or UV-inks cannot be used because of the inevitable tackiness of the resulting film. The addition of ChNCs at a content between 8 and $10 \mathrm{wt} \%$ might be a solution to alleviate this effect, while taking account their effective emulsifying action to produce waterborne coatings.

\subsection{Optical transparency}

In addition to their mechanical performance, the optical properties of nanocomposite films, namely for coating applications play a key role. The optical transparency of UV-cured AESO films was evaluated by measuring the film transmittance in the visible domain of thin film with similar thickness (Figure 10A). To avoid any effect in fluctuation in film thickness, the transmittance was normalized to a $200 \mathrm{~nm}$-thickness using the Beer-Lambert law. The unfilled AESO film has a high transparency with transmittance exceeding $90 \%$ throughout the whole visible domain of 400-800 $\mathrm{nm}$. The transmittance progressively decreased with increasing ChNC content, from $94 \%$ at $\lambda=600 \mathrm{~nm}$ for a pure AESO film to 81 and $75 \%$ at 4 and $10 \mathrm{wt} \%$ ChNC contents, respectively. The decrease in transmittance is due to light scattering at the $\mathrm{ChNC/matrix}$ interface when crossing the film. Its magnitude strongly depends on the wavelength and thickness of the object transmitted by light. Comparing the decrease in transmittance at different $\mathrm{ChNC}$ contents (Figure 10B), a rapid decrease was observed between 0 and $4 \mathrm{wt} \% \mathrm{ChNCs}$, while over $4 \mathrm{wt} \%$, the transmittance remained roughly constant indicating the maintenance of the transparency of the nanocomposite AESO-ChNC film despite the increase in nanofiller content and the honeycomb-like morphology. This evolution suggests the absence of large objects with cross-section area exceeding $100 \mathrm{~nm}$ that strongly scatter light resulting in a film opacification. ${ }^{29}$ In the picture of nanocomposite films containing 0, 2, 6 and $10 \mathrm{wt} \% \mathrm{ChNCs}$ (Figure 10C), the background image can be clearly seen through the films, indicating the persistence of their transparency.

The thin cell walls formed by the ChNCs in the honeycomb microstructure of the films did not scatter light, preventing a loss of transparency. It is worth mentioning that a stronger 
reduction in transmittance was reported for nanocomposite films produced by casting a mixture of acrylic polymer latex and CNCs (Figure 8B). ${ }^{29,30}$ The lower transmittance at shorter wavelengths, especially for 8 and $10 \mathrm{wt} \% \mathrm{ChNC}$ contents, is explained by the strong dependency on wavelength of the Mie scattering intensity from nanoscale particles $\left(I \propto 1 / \lambda^{4}\right)$, resulting in a significant decrease in transmittance at low wavelength. ${ }^{30}$
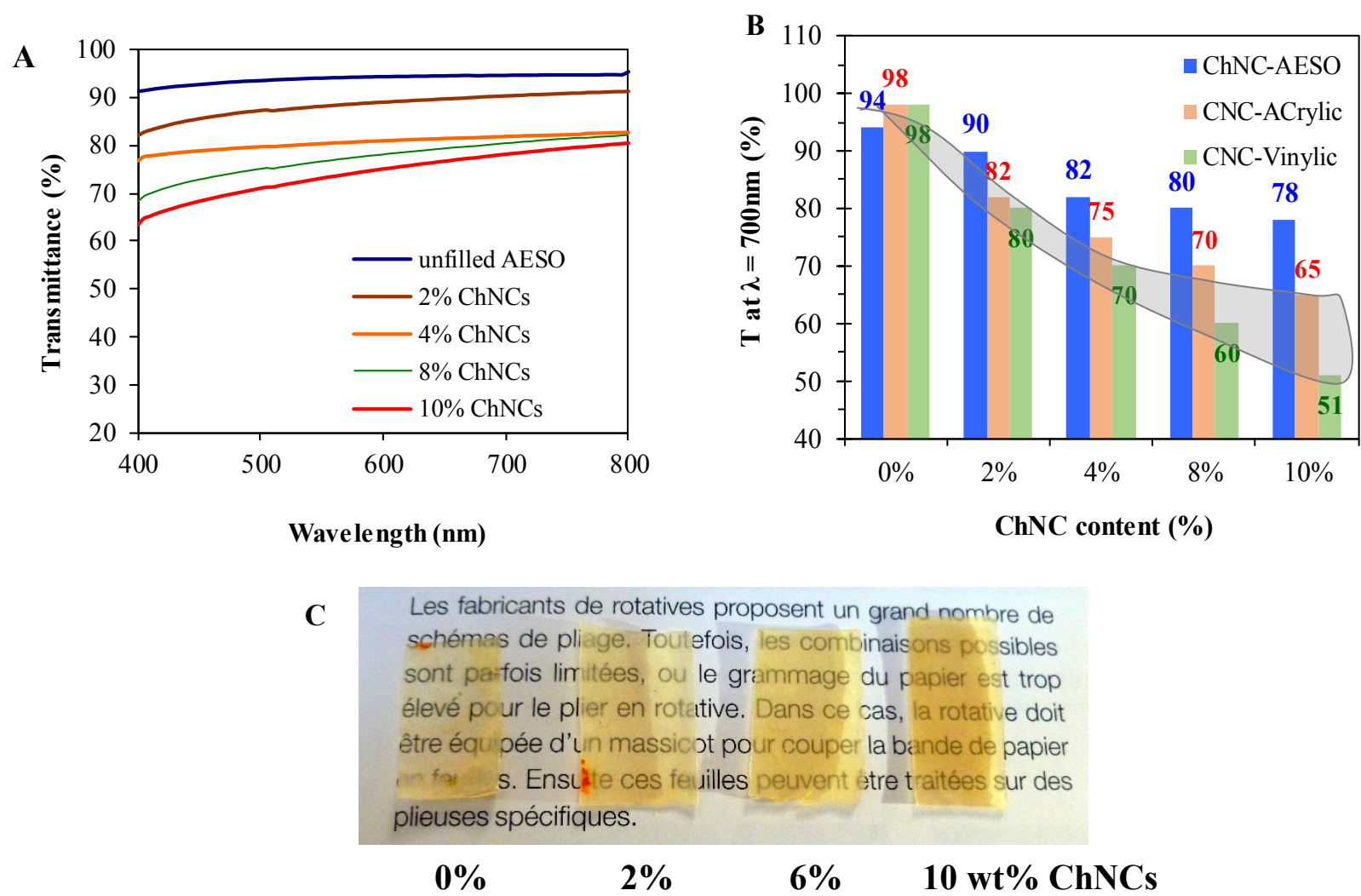

Figure 10. (A) Transmittance in the visible domain of UV-cured AESO films with different ChNC contents; (B) transmittance at $700 \mathrm{~nm}$ vs $\mathrm{ChNC}$ content compared to data from literature on acrylic or vinylic matrix containing cellulose nanocrystals (CNC), ${ }^{31,32}$ and (C) picture of UV-cured AESO films with different ChNC contents. The film thickness is about $500 \mu \mathrm{m}$.

\subsection{Solvent sensitivity}

In UV-cured coatings and thin films, the sensitivity to solvents is important to minimize staining and film removal once exposed to organic solvent. This property is easily assessed by immersing the cured films in an organic solvent and evaluate the extent of solvent absorption. Presently, the effect of ChNCs on the sensitivity to solvent was tested for toluene as typical solvent. A reduction in the swelling degree of the film after its immersion in toluene, along with a decrease in the fraction of dissolved material, was noted in films containing ChNCs (Figure 11). This improvement in swelling resistance is presumably due to the strong 
interaction between ChNCs and crosslinked AESO chains through hydrogen bonding but also to the chemical linkage between ChNCs and AESO chains after UV-curing, as deduced from DSC and DMA analyses. However, the presence of ChNCs did not completely hamper the swelling, which is likely due to cellular microstructure of the AESO-ChNC composites with ChNCs acting as a thin encapsulating layer around AESO particles.

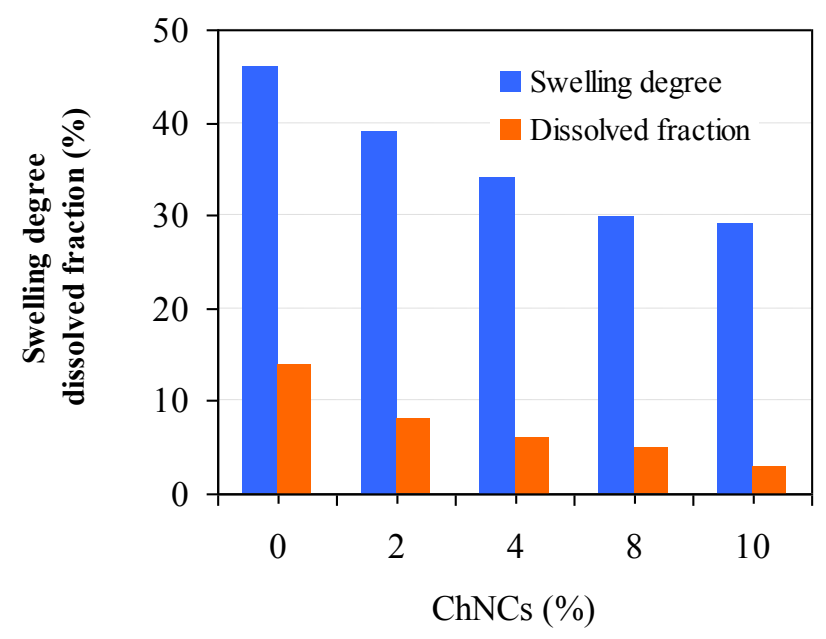

Figure 11. Swelling degree and dissolved fraction after immersion of UV-cured AESO-ChNC films at different ChNC contents in toluene for $24 \mathrm{~h}$.

\section{CONCLUSION}

Stable UV-curable waterborne Pickering AESO emulsions, solely stabilized by ChNCs, were prepared without any other additives, except the photoinitiator, and showed a good potential for coating or adhesive applications. The addition of ChNCs accelerated the photochemical curing of the film by eliminating the induction period. The curing of the dry films prepared from the emulsion resulted in a honeycomb distribution of ChNCs in the AESO matrix and an improvement of the mechanical performance, namely a significant increase in film stiffness and strength. In addition, the presence of ChNCs improved the solvent resistance by reducing the swelling of the cured film in solvents. To our knowledge, this strategy for preparing waterborne UV-curable dispersions of AESO has not been reported so far in the literature. Given the high viscosity of AESO, this would make possible the application of AESO in UV-cured biobased coating and adhesive formulations without adding any solvent or synthetic surfactant. 


\section{Acknowledgements}

The authors acknowledge LabEx Tec 21 (Investissements d'Avenir \#ANR-11-LABX-0030), as well as the PHC Utique 19G1123 and Glyco@Alps programs (Investissements d'Avenir \#ANR-15-IDEX-02) for financial support. We thank the NanoBio-ICMG Platform (UAR 2607, Grenoble) for granting access to the Electron Microscopy facility. CERMAV and LRP are part of Institut Carnot PolyNat (Investissements d'Avenir \#ANR-11-CARN-030-01). We thank Rachel Martin for SEM observations at the CMTC platform of Grenoble INP supported by LabEx CEMAM (Investissements d'Avenir \#ANR-10-LABX-44-01). 


\section{Supporting Information}
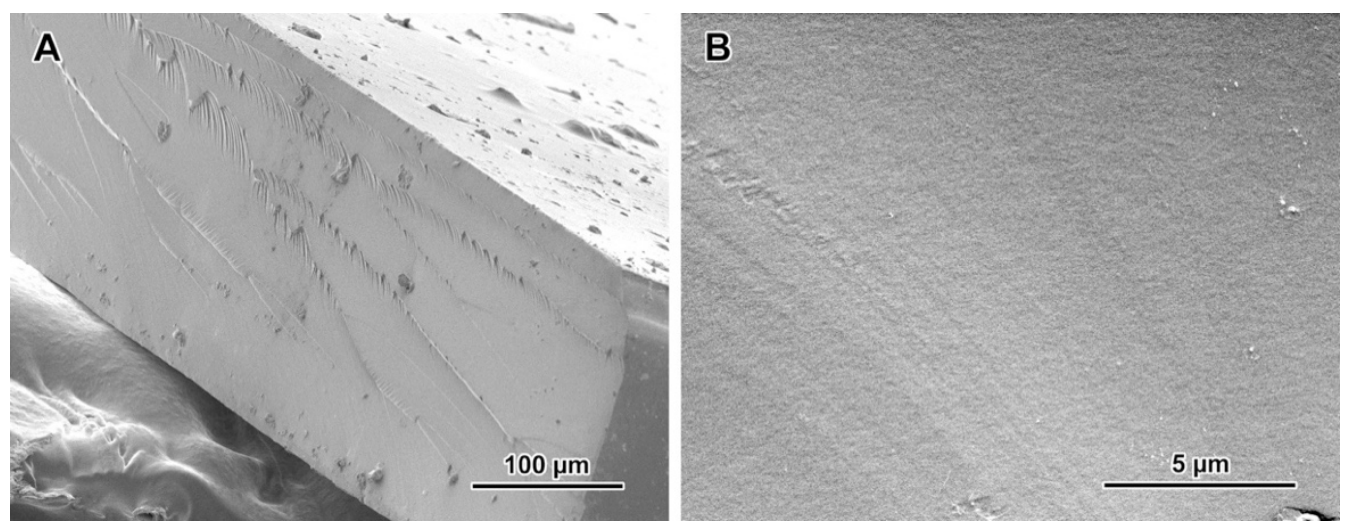

Figure S1. Secondary electron SEM images of the cross-section of a UV-cured neat AESO film fractured in liquid nitrogen.
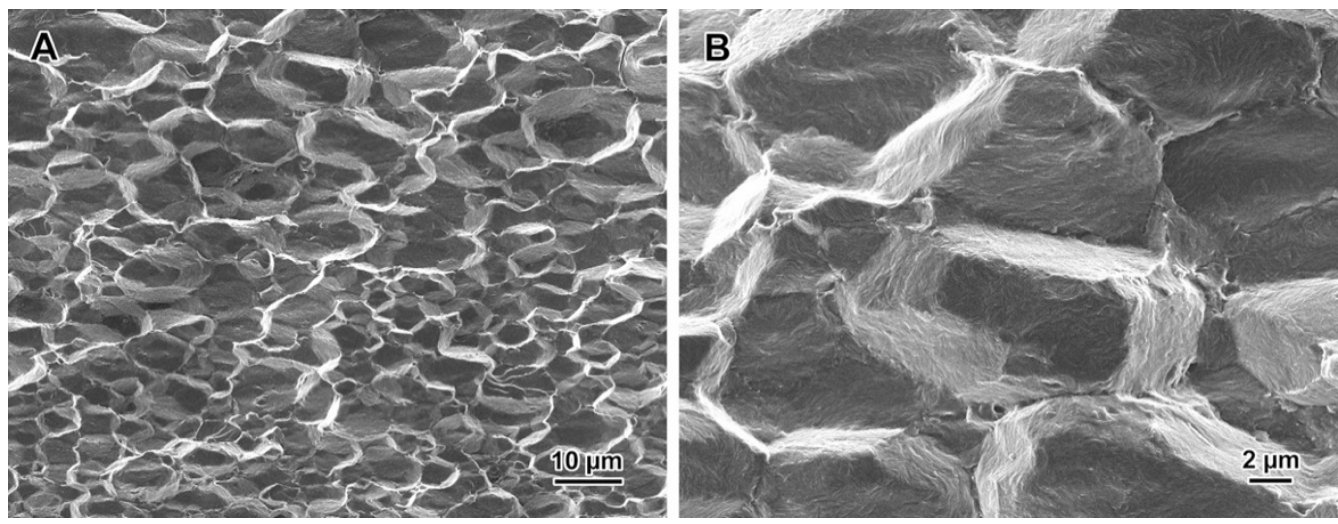

Figure S2. Secondary electron SEM images of the cross-section of a UV-cured AESO-ChNC8 film fractured in liquid nitrogen.
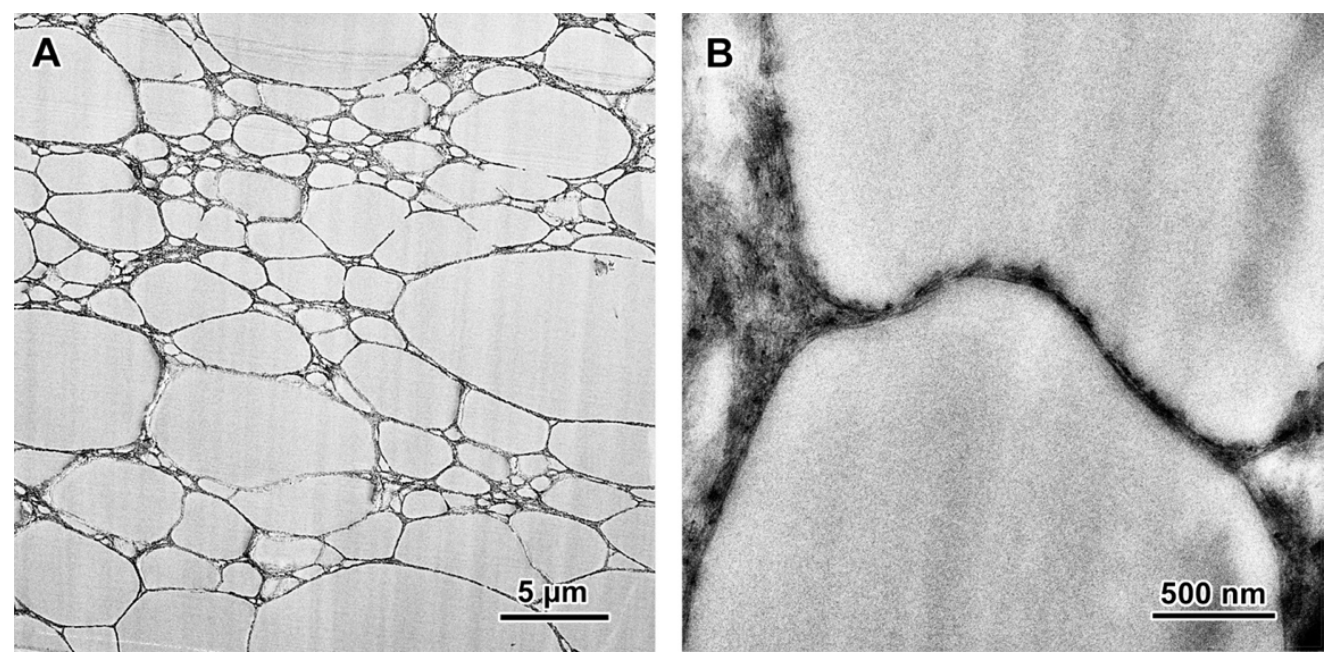

Figure S3. (A,B) Low-dose bright-field TEM images of the ultrathin cryosection of a UV-cured AESO-ChCN10 film. The cell walls appear as dark regions due to the crystalline ChNCs that generate a Bragg diffraction contrast. 

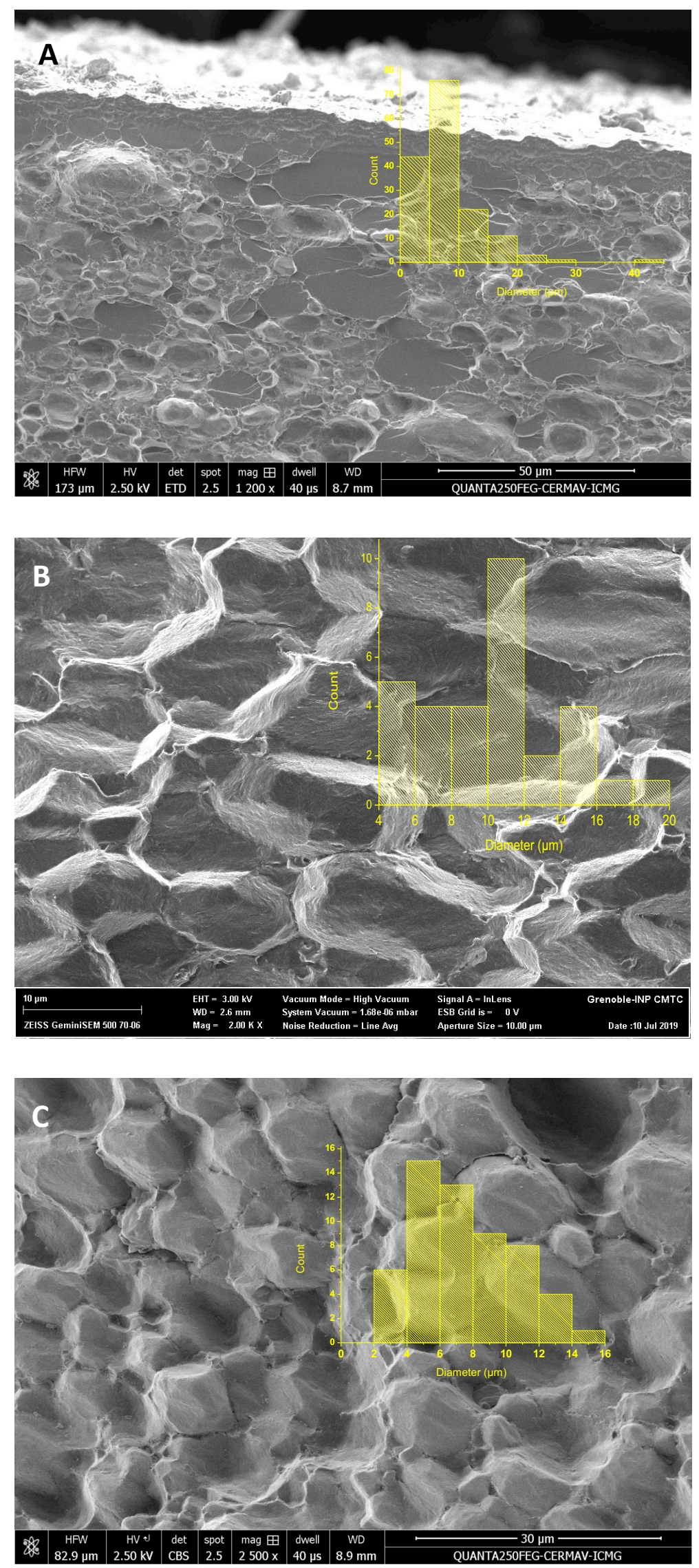

Figure S4. Cell size distribution histograms determined from SEM images of the cryofractured films using ImageJ, at different ChNC contents: (A) 4\%, (B) 8\%, and (C) 10\%. 


\section{References}

${ }^{1}$ Ligadas, G.; Ronda, J. C.; Virginia Cádiz, M. G. Renewable polymeric materials from vegetable oils: a perspective. Mater. Today 2013, 16, 337-343.

https://doi.org/10.1016/j.mattod.2013.08.016

${ }^{2}$ Williams, C. K.; Hillmyer, M. A. Polymers from renewable resources: a perspective for a special issue of Polymer Reviews. Polym. Rev. 2008, 48, 1-10. http://dx.doi.org/10.1080/15583720701834133

${ }^{3}$ Zhang, C.; Garrison, T. F.; Madbouly, S. A.; Kesslerb, M. R. Recent advances in vegetable oil-based polymers and their composites. Prog. Polym. Sci. 2017, 71, 91-143. https://doi.org/10.1016/j.progpolymsci.2016.12.009

${ }^{4}$ Fertier, L.; Koleilat, H.; Stemmelen, M.; Giani, O.; Joly-Duhamel, C.; Lapinte, V.; Robin, J.-J. The use of renewable feedstock in UV-curable materials - A new age for polymers and green chemistry. Prog. Polym. Sci. 2013, 38, 932-962.

https://doi.org/10.1016/j.progpolymsci.2012.12.002

${ }^{5}$ Athawale, V. D.; Nimbalkar, R. V., Waterborne coatings based on renewable oil resources: an overview. J. Am. Oil Chem. Soc. 2011, 88, 159-185. https://doi.org/10.1007/s11746010-1668-9.

${ }^{6}$ Lin, N.; Huang, J.; Dufresne, A. Preparation, properties and applications of polysaccharide nanocrystals in advanced functional nanomaterials: a review. Nanoscale 2012, 4, 32743294. https://doi.org/10.1039/C2NR30260H

${ }^{7}$ Zhao, X.; Wan, Q.; Fu, X.; Meng, X.; Ou, X., Zhong, R., Zhou, Q.; Liu, M. Toxicity evaluation of one-dimensional nanoparticles using Caenorhabditis elegans: A comparative study of halloysite nanotubes and chitin nanocrystals, ACS Sustain. Chem. Eng. 2019, 7, 18965-18975. https://doi.org/10.1021/acssuschemeng.9b04365

${ }^{8}$ Tzoumaki, M. V.; Moschakis, T.; Kiosseoglou, V.; Biliaderis, C. G. Oil-in-water emulsions stabilized by chitin nanocrystal particles. Food Hydrocoll. 2011, 25, 1521-1529. https://doi.org/10.1016/j.foodhyd.2011.02.008

${ }^{9}$ Wang, X.; Liang, K.; Tian, Y.; Ji, Y. A facile and green emulsion casting method to prepare chitin nanocrystal reinforced citrate-based bioelastomer. Carbohydr. Polym. 2017, 157, 620-628. https://doi.org/10.1016/j.carbpol.2016.10.034

${ }^{10}$ Huang, Y.; Yang, J.; Chen, L.; Zhang, L, Chitin nanofibrils to stabilize long-life Pickering foams and their application for lightweight porous materials. ACS Sustain. Chem. Eng. 2018, 6, 10552-10561. https://doi.org/10.1021/acssuschemeng.8b01883

${ }^{11}$ Perrin, E.; Bizot, H.; Cathala, B.; Capron, I, Chitin nanocrystals for Pickering high internal phase emulsions. Biomacromolecules 2014, 15, 3766-3771. https://doi.org/10.1021/bm5010417

${ }^{12}$ Dickinson, E. Biopolymer-based particles as stabilizing agents for emulsions and foams. Food Hydrocoll. 2017, 68, 219-231. https://doi.org/10.1016/j.foodhyd.2016.06.024

${ }^{13}$ Ben Cheikh, F.; Ben Mabrouk, A.; Magnin, A.; Putaux, J.-L.; Boufi, S. Chitin nanocrystals as Pickering stabilizer for O/W emulsions: Effect of the oil chemical structure on the emulsion properties. Colloid Surface B 2021, 200, 111604. https://doi.org/10.1016/j.colsurfb.2021.111604

${ }^{14}$ Li, J.; Revol, J.-F.; Naranjo, E.; Marchessault, R. H. Effect of electrostatic interaction on phase separation behaviour of chitin crystallite suspensions. Int. J. Biol. Macromol. 1996, 18, 177-187. https://doi.org/10.1016/0141-8130(95)01066-1 
${ }^{15}$ Salih, A. M.; Bin Ahmad, M.; Ibrahim, N. A.; Hj Mohd Dahlan, K. Z., Tajau, R.; Mahmood, M. H.; Zin Wan Yunus, W. M. Synthesis of radiation curable palm oilbased epoxyacrylate: NMR and FTIR spectroscopic investigations. Molecules 2015, 20, 14191-14211. https://doi.org/10.3390/molecules200814191

${ }^{16}$ Wu, Q.; Hu, Y.; Tang, J.; Zhang, J.; Wang, C.; Shang, Q.; Feng, G.; Liu, C.; Zhou, Y.; Lei,W. High-performance soybean-oil-based epoxy acrylate resins: "Green" synthesis and application in UV-curable coatings, ACS Sustainable Chem. Eng. 2018, 6, 8340-8349. https://doi.org/10.1021/acssuschemeng.8b00388

${ }^{17}$ Cramer, N. B.; O’Brien, C. P.; Bowman, C. N. Mechanisms, polymerization rate scaling, and oxygen inhibition with an ultrarapid monovinyl urethane acrylate. Polymer 2008, 49, 4756-4761. https://doi.org/10.1016/j.polymer.2008.08.051

${ }^{18} \mathrm{Wu}$, J.; Zhang, K.; Girouard, N.; Meredith, J. C., Facile route to produce chitin nanofibers as precursors for flexible and transparent gas barrier materials, Biomacromolecules 2014, 15, 4614-4620. https://doi.org/10.1021/bm501416q

${ }^{19}$ Zhong, T.; Wolcott, M.P.; Liu, H.; Wang, W. Developing chitin nanocrystals for flexible packaging coatings. Carbohydr. Polym. 2019, 226, 115276.

https://doi.org/10.1016/j.carbpol.2019.115276

${ }^{20}$ Limousin, E.; Rafaniello, I.; Schäfer, T.; Ballard, N.; Asua, J. M. Linking film structure and mechanical properties in nanocomposite films formed from dispersions of cellulose nanocrystals and acrylic latexes. Langmuir 2020, 36, 2052-2062. https://dx.doi.org/10.1021/acs.langmuir.9b03861

${ }^{21}$ Negrete-Herrera, N.; Putaux, J.-L.; David, L.; De Haas, F.; Bourgeat-Lami, E. Polymer/Laponite composite latexes: particle morphology, film microstructure, and properties. Macromol. Rapid Comm. 2007, 28, 1567-1573. https://doi.org/10.1002/marc.200700212

${ }^{22}$ Liu, Y.; Liu, M.; Yang, S.; Luo, B.; Zhou, C. Liquid crystalline behaviors of chitin nanocrystals and their reinforcing effect on natural rubber. ACS Sustain. Chem. Eng. 2018, 6, 325-336. https://doi.org/10.1021/acssuschemeng.7b02586

${ }^{23}$ Cheng, B.; Pei, B.; Wang, Z.; Hu, Q. Advances in chitosan-based superabsorbent hydrogels. $R S C A d v$. 2017, 7, 42036. https://doi.org/10.1039/C7RA07104C

${ }^{24}$ Azizi Samir, M. A. S.; Alloin, F.; Dufresne, A. Review of recent research into cellulosic whiskers, their properties and their application in nanocomposite field. Biomacromolecules 2005, 6, 612-626. https://doi.org/10.1021/bm0493685

${ }^{25}$ Wu, Y.P.; Jia, Q.X.; Yu, D. S.; Zhang, L. Q. Modeling Young's modulus of rubber-clay nanocomposites using composite theories. Polym. Test. 2004, 23, 903-909. https://doi.org/10.1016/j.polymertesting.2004.05.004

${ }^{26} \mathrm{Xu}, \mathrm{W}$.; Mulhern, P. J.; Blackford, B. L.; Jericho, M. H.; Templeton, I. A new atomic force microscopy technique for the measurement of the elastic properties of biological materials of the elastic properties of biological materials. Scanning Microsc. 1994, 8, 499-506. https://digitalcommons.usu.edu/microscopy/vol8/iss3/8

${ }^{27}$ Dufresne, A. Comparing the mechanical properties of high performances polymer nanocomposites from biological sources. J. Nanosci. Nanotechnol. 2006, 6, 322-330. https://doi.org/10.1166/jnn.2006.906

${ }^{28}$ Gibson, L. J. Biomechanics of cellular solids. J. Biomech. 2005, 38, 377-399. https://doi.org/10.1016/j.jbiomech.2004.09.027 
${ }^{29}$ Li, S.; Lin, M. M.; Toprak, M. S.; Kim, D. K.; Muhammed, M. Nanocomposites of polymer and inorganic nanoparticles for optical and magnetic applications. Nano Rev. 2010, 1 , 5214. https://doi.org/10.3402/nano.v1i0.5214

${ }^{30}$ Althues, H.; Henle, A.; Kaskel, S. Functional inorganic nanofillers for transparent polymers. Chem. Soc. Rev. 2007, 36, 1454-1465. https://doi.org/10.1039/B608177K

${ }^{31}$ Boufi, S.; Kaddami, H.; Dufresne, A. Mechanical performance and transparency of nanocellulose reinforced polymer nanocomposites. Macromol. Mat. Eng. 2014, 299, 560-568. https://doi.org/10.1002/mame.201300232

32 Ben Mabrouk, A.; Dufresne, A.; Boufi, S. Cellulose nanocrystal as ecofriendly stabilizer for emulsion polymerization and its application for waterborne adhesive. Carbohydr. Polym. 2020, 229, 115504. https://doi.org/10.1016/j.carbpol.2019.115504 